Louise Oliveira Ramos Machado (iD) https://orcid.org/0000-0002-3364-7930 Rita Franco Rego a

iD https://orcid.org/0000-0002-0632-4546 Gerluce Alves Silva ${ }^{\mathrm{b}}$

(D) https://orcid.org/0000-0002-0978-3393

Juliana dos Santos Müiller ${ }^{C}$

iD http://orcid.org/0000-0002-8593-304X

Ila Rocha Falcão ${ }^{d}$

(D) http://orcid.org/0000-0001-6961-3858

a Universidade Federal da Bahia (UFBA), Faculdade de Medicina da Bahia, Programa de Pós-Graduação em Saúde, Ambiente e Trabalho. Salvador, BA, Brasil.

b Secretaria de Saúde do Estado da Bahia. Salvador, BA, Brasil.

' Instituto Federal de Educação, Ciência e Tecnologia de Santa Catarina. Florianopolis, SC, Brasil.

d Universidade Federal da Bahia (UFBA), Programa de Pós-Graduação em Alimentos, Nutrição e Saúde. Salvador, BA, Brasil.

Contato:

Rita Franco Rego

E-mail:

ritarego@ufba.br

As autoras informam que a pesquisa obteve financiamento, por edital, do Fundo Nacional de Saúde do Ministério da Saúde para estudos e pesquisas voltados a acões de vigilância e prevenção da saúde do trabalhador, através do termo de cooperação entre Ministério da Saúde e Universidade Federal da Bahia no 291/2013, e contou com a colaboração da Secretaria

Municipal de Saúde de Santo Amaro, da Diretoria de Vigilância e Atenção à Saúde do Trabalhador (Divast) e da Diretoria de Vigilância Sanitária e Ambiental (Divisa) do estado da Bahia. O presente trabalho foi realizado com apoio da Coordenação de Aperfeiçoamento de Pessoal de Nível Superior - Brasil (CAPES) Código de Financiamento 001.

As autoras declaram que não há conflitos de interesses.

As autoras informam que o trabalho não foi apresentado em evento científico e foi baseado na dissertação de mestrado de Louise Oliveira Ramos Machado, apresentada em 2017 ao Programa de Pós-Graduação em Saúde, Ambiente e Trabalho da Universidade Federal da Bahia (UFBA), em Salvador, Bahia.

Recebido: 28/12/2018

Revisado: 25/01/2019

Aprovado: 25/03/2019

\section{Avaliação da implantação do Protocolo de Vigilância e Atenção à Saúde de ex-trabalhadores e da população expostos a chumbo, cádmio, cobre e zinco em Santo Amaro, Bahia, Brasil}

\author{
Assessing the implementation of the Surveillance and Health \\ Care Protocol of former workers and the population exposed to \\ lead, cadmium, copper and zinc in Santo Amaro, Bahia, Brazil
}

\section{Resumo}

Objetivo: aferir o grau de implantação do Protocolo de Vigilância e Atenção à Saúde de ex-trabalhadores e da população expostos a chumbo, cádmio, cobre e zinco em Santo Amaro, Bahia, no período de 2010 a 2015. Métodos: foram elaborados modelo lógico de avaliação e instrumentos de coleta de dados a fim de avaliar a estrutura, o processo e o resultado da implantação do Protocolo. O método Delphi adaptado foi utilizado como técnica de consenso para garantir a validade do conteúdo e da matriz de julgamento. Resultados: o escore final da avaliação foi de $22,3 \%$, considerado insatisfatório, segundo a escala adotada. A "estrutura" obteve 38 pontos do total de 100; o "processo", baseado na dimensão "organização e execução das atividades previstas no Protocolo", obteve 25 pontos de 100; e a abordagem "resultados" alcançou 4 pontos de 100 . Apenas $2,5 \%$ da população prevista pelo Protocolo teve as fichas de atendimento preenchidas, porém com falhas no atendimento, na realização de exames e nas notificações ao Sistema de Informação de Agravos de Notificação. Conclusão: o processo de implantação do Protocolo necessita de maior empenho da gestão pública de saúde, e de melhoria na infraestrutura, nas estratégias de orientação das equipes de saúde e na participação do usuário.

Palavras-chave: avaliação em saúde; contaminantes ambientais; vigilância ambiental em saúde; atenção primária à saúde; saúde do trabalhador.

\begin{abstract}
Objective: to assess the implementation of the Surveillance and Health Care Protocol for former workers and population exposed to lead, cadmium, copper and zinc in Santo Amaro, Bahia, between 2010 and 2015. Methods: we designed a logical evaluation model and data collection instruments to assess the structure, process and results of the protocol implementation. We used the adapted Delphi method as a consensus technique to ensure the validity of content and the judgment matrix. Results: the evaluation final score was $22.3 \%$, considered not satisfactory according to the adopted scale. The "structure" rendered 38 points out of 100; the "process" (related to the dimension "organization and execution of the activities foreseen by the protocol") rendered 25 points out of 100; and "results" rendered 4 points out of 100. Only 2.5\% of the Protocol covered population had assistance forms filled. Moreover, there were failures in attendance, exams and notifications to the Sistema de Informação de Agravos de Notificação [National Disease Notification System]. Conclusion: the protocol implementation process needs greater commitment from the public health management, improved infrastructure, and better strategies for health care teams and for the population participation.
\end{abstract}

Keywords: health evaluation; environmental pollutants; environmental health surveillance; primary health care; occupational health. 


\section{Introdução}

Durante o período de 1960 a 1993, a Companhia Brasileira de Chumbo (Cobrac) atuou na produção de lingotes de chumbo no município de Santo Amaro. Nesse período, foram produzidas cerca de 490 mil toneladas de escória contendo em seu peso até 4\% de óxido de chumbo (PbO), traços de cádmio (Cd) e outros metais ${ }^{1}$. Esses elementos, a depender da concentração ambiental, duração da exposição e dose absorvida, podem ocasionar efeitos danosos à saúde da população ${ }^{2}$. Conforme estudos recentes, apesar de a planta industrial ter interrompido suas emissões há mais de 20 anos, os elementos potencialmente tóxicos chumbo $(\mathrm{Pb})$, cádmio $(\mathrm{Cd})$, zinco $(\mathrm{Zn})$, cobre $(\mathrm{Cu})$, arsênio (As) e prata (Ag) - ainda estão concentrados na camada de $10 \mathrm{~cm}$ superior do solo, o que justifica a importância do monitoramento contínuo da saúde da população residente em Santo Amaro ${ }^{3}$.

Ao longo de 40 anos, pesquisas evidenciaram a contaminação da cidade de Santo Amaro, constatando elevados níveis de chumbo em trabalhadores, pescadores e crianças, como demonstram estudos epidemiológicos realizados de 1975 a $2003^{4}$, registrando-se também contaminação de solo, água, vegetais e poeira domiciliar ${ }^{5,6}$.

Há diversas evidências científicas de que ex-trabalhadores da Cobrac e a população de Santo Amaro estão expostos a contaminantes que podem gerar danos à saúde ${ }^{4}$. Em 1989, a COBRAC foi vendida e passou a denominar-se Plumbum Mineração e Metalurgia Ltda.. Segundo o relatório de avaliação de risco de $2003^{6}$, foram considerados expostos em Santo Amaro, até aquela data: a população moradora do entorno da Plumbum (num raio de $500 \mathrm{~m}$ ), a população consumidora de moluscos (em especial famílias de pescadores da colônia de Caieiras), os ex-trabalhadores e os trabalhadores em atividades de risco atual e passado de exposição a metais pesados e suas respectivas famílias, perfazendo um total de 2.570 famílias. O mesmo documento faz uma série de recomendações, como a necessidade de avaliação de saúde, estudos de indicadores biológicos de exposição e efeitos, e a organização de um Programa de Vigilância e Atenção à Saúde ${ }^{6}$.

Diante desse contexto, num esforço conjunto das três esferas governamentais, foi instituído em 2010 o Protocolo de Vigilância e Atenção à Saúde da População Exposta ao Chumbo, Cádmio, Cobre e Zinco em Santo Amaro, Bahia, doravante denominado Protocolo, com o propósito de desenvolver ações para a melhoria da qualidade de vida e a redução de danos causados pela exposição aos contaminantes, primando pela assistência à saúde no âmbito da atenção básica por meio da Estratégia Saúde da Família (ESF) ${ }^{5}$.

Figueiredo e Tanaka ${ }^{7}$ destacam que a avaliação de programas é necessária para reordenar o sistema de saúde e construir atos de medição, comparação e emissão de juízo de valor, sendo útil para fundamentar decisões e integrar ações de assistência, como também para contribuir com a prevenção e a promoção da saúde, considerando sua dimensão técnico-política.

Champagne et al. ${ }^{8}$ referem-se à existência de dois tipos de avaliação, os quais podem ser aplicados a qualquer intervenção: a pesquisa avaliativa, um procedimento científico que permite a análise e compreensão das relações de causalidade entre os distintos componentes da intervenção; e a avaliação normativa, que utiliza critérios e normas para emissão de um juízo de valor a respeito da intervenção. Essa avaliação tem como propósito fazer um julgamento sobre uma intervenção e, para tanto, compara os recursos empregados e sua organização (estrutura), os serviços ou os bens produzidos (processo) e os resultados obtidos, com critérios, normas e padrões definidos.

O estudo da estrutura reflete em que medida os recursos despendidos estão adequados para atingir os resultados esperados, realizando a comparação dos recursos da intervenção, bem como de sua organização, com critérios e normas. A avaliação de processo refere-se à apreciação dos serviços oferecidos pelo programa ou pela intervenção, comparando as normas estabelecidas em função dos resultados pretendidos. E, por fim, a apreciação dos resultados se processa ao questionar se os resultados observados condizem com os esperados, ou seja, se os objetivos da intervenção foram alcançados ${ }^{9}$.

No sistema de saúde, a avaliação busca auxiliar na tomada de decisões, podendo apontar problemas e redirecionar ações e serviços em curso; avaliar a introdução de novos procedimentos na prática profissional; e dimensionar o impacto das ações implementadas sobre a saúde da população ${ }^{10}$.

Hartz et al. ${ }^{11}$ afirmam que a relevância de avaliar a implantação mostra-se como condição fundamental para conhecer a totalidade das intervenções nos aspectos ligados à validade do seu conteúdo (adequação dessas intervenções às normas) e aos elementos explicativos das discrepâncias entre ações planejadas e executadas. Nesse tipo de avaliação é preciso, a princípio, conceber a teoria do programa, discriminando os componentes, as práticas e o contexto necessário como etapas prévias aos resultados esperados.

Este estudo tem como objetivo realizar uma avaliação normativa para aferir o grau de implantação alcançado pelas estratégias do Protocolo de Vigilância e Atenção à Saúde da População Exposta ao Chumbo, Cádmio, Cobre e Zinco em Santo Amaro, Bahia.

\section{Métodos}

\section{População e área de estudo}

Santo Amaro é um município localizado a $73 \mathrm{~km}$ de Salvador e possui área aproximada de 492,916 km². 
Em 2010, possuía uma população de 57.811 habitantes, dos quais $77,4 \%$ residiam em zona urbana, e $22,6 \%$ em zona rural ${ }^{12}$. Sua densidade demográfica é de 117,26 habitantes $/ \mathrm{km}^{2}$. O município é tido como um dos mais contaminados por chumbo no mundo ${ }^{13}$.

O Protocolo reconhece como foco de atenção a população moradora do entorno da Plumbum, num raio de 500 metros, contabilizando aproximadamente 1.220 famílias; a população consumidora de moluscos, principalmente 150 famílias de pescadores da colônia de Caieiras; e cerca de 1.200 ex-trabalhadores da Plumbum e demais trabalhadores expostos e seus respectivos familiares, perfazendo um total de 2.570 famílias que deveriam ser atendidas pelas Unidades de Saúde da Família (USF). Levando-se em conta a média de 3,37 pessoas por família, segundo o censo de $2010^{12}$, estimou-se que 8.661 pessoas deveriam ser atendidas. Como a população de Santo Amaro, conforme o mesmo censo $^{12}$, era de 57.811 pessoas, esse valor representava $15 \%$ da população total de Santo Amaro. Ressalta-se ainda que outras pessoas poderiam ser identificadas como expostas no curso dos atendimentos, o que poderia aumentar o número de indivíduos previsto inicialmente no Protocolo $(8.661)^{5}$.

\section{Desenho do estudo}

Trata-se de estudo avaliativo que tem por objetivo aferir o grau de implantação do Protocolo de Vigilância e Atenção à Saúde da População Exposta ao Chumbo, Cádmio, Cobre e Zinco em Santo Amaro, Bahia.
O município de Santo Amaro contava, no período pesquisado - de janeiro a abril de 2015 -, com 13 USF. Entretanto, durante a realização do estudo, duas unidades estavam desativadas (USF Professor José Silveira e USF Berchris Moura Requião), quatro não aplicavam o Protocolo, pois as coordenadoras não detinham o conhecimento necessário para tanto (USF Doutor Clodomir Azevedo Lopes, localizada no distrito de Pedra; USF Luzia Oliveira Souza, localizada no distrito Tanque de Senzala; USF Anibal Senna e USF Valter de Figueredo, localizadas no Sítio Camaçari), e duas estavam com novos coordenadores que não haviam recebido treinamento nem souberam informar acerca das estratégias do Protocolo. Em cinco unidades os coordenadores foram entrevistados por meio de um formulário que abordava aspectos da avaliação normativa do Protocolo, sendo elas: USF Doutora Elvira de Araújo Queiroz, USF Doutor Antônio Balbino, USF Renato Augusto Pedreira Leoni, USF Doutor Ranulpho Paranhos e USF Clóvis da Silva Lopes, localizadas respectivamente nos bairros Sacramento, Caixa d'Água, Derba, Trapiche e no distrito de São Brás.

Para aferir o grau de implantação do Protocolo, foi elaborado um modelo lógico de avaliação (Figura 1) que apresenta a intervenção proposta, considerando as inter-relações entre estrutura, processo e resultado. Esse tipo de esquema lógico permite a melhor visualização da intervenção, que é o objeto da avaliação, permitindo a definição do que pode ser mensurável e da contribuição do Protocolo na obtenção dos resultados $^{11}$. A partir do modelo lógico foram desenvolvidos os instrumentos de coleta de dados, que abrangem as abordagens de estrutura, processo e resultado.

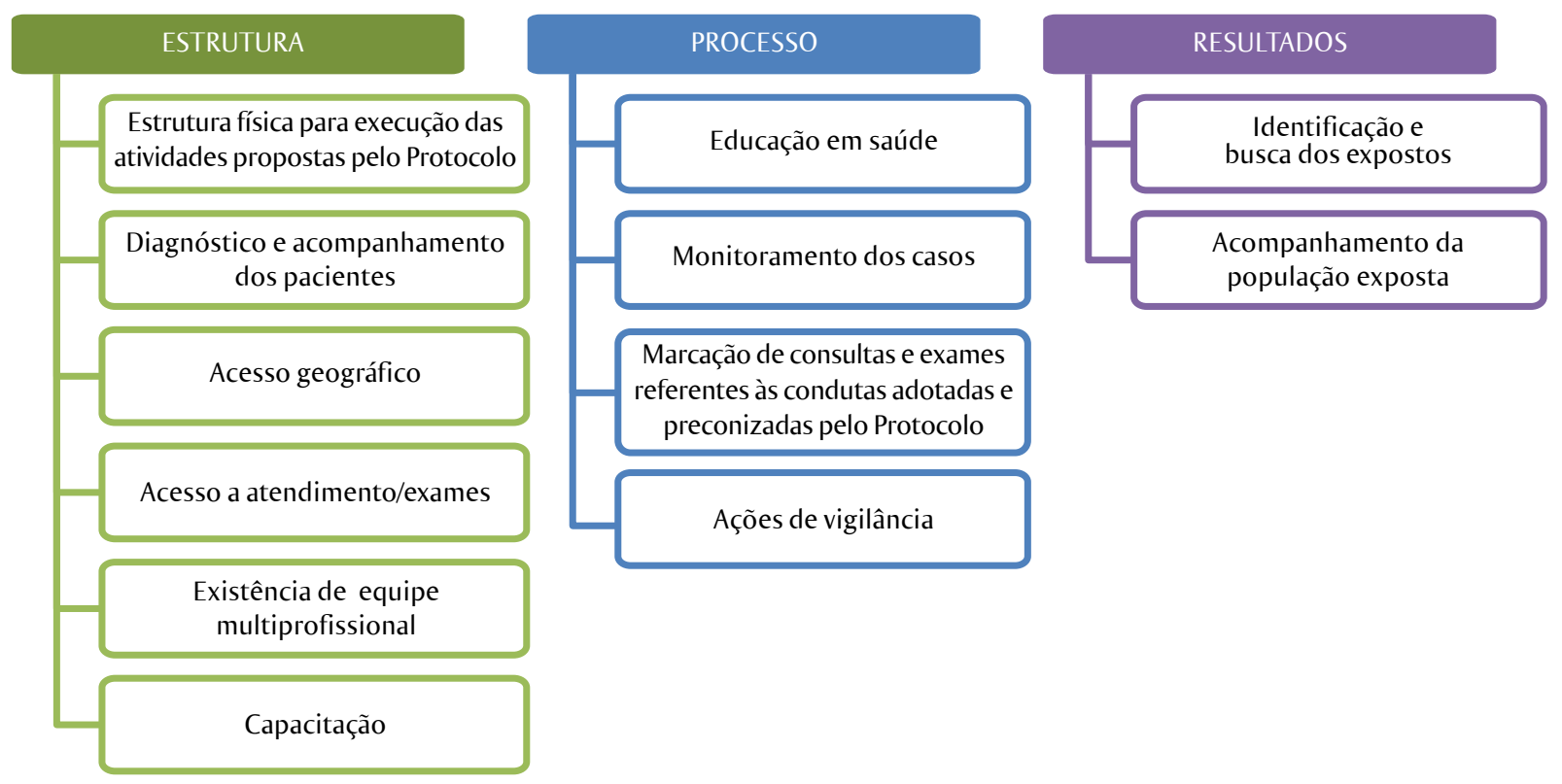

Figura 1 Modelo lógico para aferição do grau de implantação do Protocolo de Vigilância e Atenção à Saúde da População Exposta ao Chumbo, Cádmio, Cobre e Zinco em Santo Amaro, Bahia, Brasil 
Com base no modelo lógico, foi construída uma matriz de julgamento (Quadro 1) na qual foram elencados dimensões, critérios e padrões de julgamento para cada abordagem. O processo de desenvolvimento do instrumento foi realizado em etapas, conforme a Figura 2. A primeira etapa envolveu uma revisão integrativa e documental, e a segunda um estudo qualitativo, com entrevistas na modalidade semiestruturada, que resultou em outro artigo ${ }^{14}$. Para garantir a validade do conteúdo e definir o modelo lógico e a matriz de julgamento, foi utilizada a técnica de consenso do método Delphi modificado ${ }^{15}$.
O método Delphi tem por objetivo a dedução e o refinamento de opiniões de um grupo de experts ou indivíduos especialmente instruídos com o intuito de alcançar o consenso entre elas ${ }^{16}$. A construção dos critérios e padrões foi definida a partir da consulta a cinco especialistas: dois envolvidos no processo de implantação desde a sua formulação e com experiência de atuação na área de vigilância ambiental; e três com experiência em avaliação de programas em vigilância ambiental. Foram realizadas duas rodadas de encontros individuais com cada especialista, além de duas comunicações por via eletrônica (Figura 2).

Quadro 1 Matriz de julgamento da implantação do Protocolo de Vigilância e Atenção à Saúde da População Exposta ao Chumbo, Cádmio, Cobre e Zinco em Santo Amaro, Bahia, Brasil

\begin{tabular}{|c|c|c|c|c|}
\hline Abordagem & Dimensão & Critérios & Pontuação & Padrão de julgamento \\
\hline \multirow{4}{*}{ 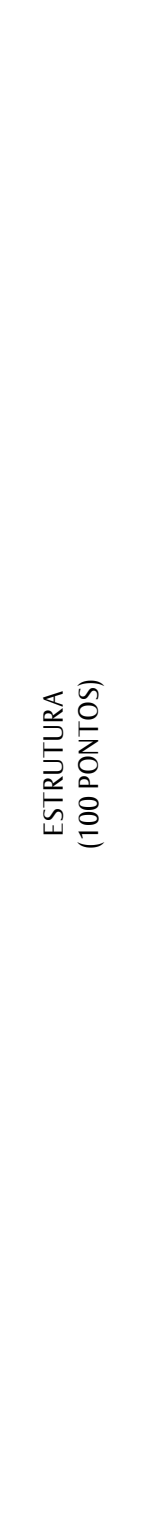 } & \multirow{2}{*}{ 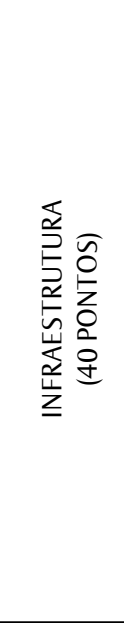 } & $\begin{array}{l}\text { Estrutura física } \\
\text { para execução } \\
\text { das atividades } \\
\text { propostas pelo } \\
\text { Protocolo } \\
\text { (20 pontos) }\end{array}$ & $\begin{array}{l}C=20 \\
P C=1-19 \\
N C=0\end{array}$ & $\begin{array}{l}\text { - } \quad \text { Ambientes para atendimento individualizado (salas para consultas } \\
\text { de enfermagem, médicas, odontológicas); } \\
\text { - } \quad \text { Ambiente para atendimento coletivo (salas para atividades de } \\
\text { educação em saúde, reuniões); } \\
\text { - Salas suficientes para atender à população (no mínimo 3); } \\
\text { - Salas de espera (recepção) adequadas para acomodar os usuários } \\
\text { (cadeiras confortáveis, ventiladores/ares-condicionados); } \\
\text { - Recursos materiais suficientes para realizar marcação de exames } \\
\text { preliminares e específicos (telefone, computador, comunicação } \\
\text { com a regulação municipal). }\end{array}$ \\
\hline & & $\begin{array}{l}\text { Diagnóstico e } \\
\text { acompanhamento } \\
\text { dos pacientes } \\
\text { (20 pontos) }\end{array}$ & $\begin{array}{l}C=20 \\
P C=1-19 \\
N C=0\end{array}$ & $\begin{array}{l}\text { - Capacidade de realizar exames de detecção de metais pesados } \\
\text { (chumbo, cádmio, cobre e zinco) no sangue (conformidade: } \\
2.400 \text { exames/ano); } \\
\text { - Capacidade de realizar avaliação médica inicial (conformidade: } \\
6 \text { mil/ano); } \\
\text { - Capacidade de realizar atendimento dos ex-trabalhadores } \\
\text { da Plumbum - total de } 1.200 \text { trabalhadores (conformidade: } 960 / a n o) ; \\
\text { Disponibilidade de laboratório próprio ou conveniado para a realização } \\
\text { de exames indicados pelo protocolo. }\end{array}$ \\
\hline & \multirow[b]{2}{*}{ 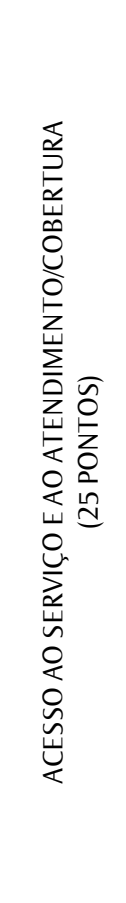 } & $\begin{array}{l}\text { Acesso geográfico } \\
\text { (5 pontos) }\end{array}$ & $\begin{array}{l}C=5 \\
P C=1-4 \\
N C=0\end{array}$ & $\begin{array}{l}\text { - } \quad \text { Serviço bem localizado e de fácil acesso (USF); } \\
\text { - } \quad \text { Acesso fácil a laboratórios ou postos de coleta (âmbito municipal). }\end{array}$ \\
\hline & & $\begin{array}{l}\text { Acesso a } \\
\text { atendimento/ } \\
\text { exames } \\
\text { (20 pontos) }\end{array}$ & $\begin{array}{l}C=20 \\
P C=1-19 \\
N C=0\end{array}$ & $\begin{array}{l}\text { - Verificar nas fichas de avaliação das condições de saúde o registro de } \\
\text { avaliação médica (padrão esperado: existência de avaliação médica em } \\
\text { todas as } 217 \text { fichas coletadas); } \\
\text { - } \quad \text { (úmero de exames preliminares disponíveis para marcação na USF. } \\
\text { Segundo o Protocolo, um total de } 5 \text { exames preliminares devem ser } \\
\text { realizados: hemograma; sumário de urina, ureia e creatinina; aspartato } \\
\text { aminotransferase (AST); alanina aminotransferase (ALT); e quantificação } \\
\text { dos metais no sangue (chumbo, cádmio, cobre e zinco). Padrão: C: } \\
\text { todos os exames; PC: 1-4 exames; NC: nenhum exame; } \\
\text { Número de exames complementares disponíveis para a realização: } \\
\text { eletroforese de hemoglobina; TSH; dosagem de arsênico na urina; } \\
\text { ferro sérico; cortisol; ALA-U; transferrina; testosterona; ECG (em } \\
\text { crianças); PSA; FSH; raio X (em crianças e adultos); Gama GT; LH; } \\
\text { USG morfológica (gestantes); bilirrubinas; PCR; USG abdome com } \\
\text { Doppler; amilase; látex; USG de próstata; coagulograma; ácido úrico; } \\
\text { eletroneuromiografia; fosfatase alcalina; espermograma; densitometria } \\
\text { óssea; T3; T4 livre; mielograma; e audiometria. Padrão: C: todos os } \\
\text { exames (30); PC: 1-29 exames; NC: nenhum exame; ou não se aplica; } \\
\text { Número de especialidades médicas disponíveis para marcação de } \\
\text { consultas (angiologia, cardiologia, clínica cirúrgica, dermatologia, } \\
\text { endocrinologista, gastroenterologia, hematologia, infectologia, } \\
\text { neurologia, obstetrícia, oftalmologia, oncologia, ortopedia e } \\
\text { traumatologia, pediatria, pneumologia, psiquiatria, reumatologia, } \\
\text { e urologia). Padrão: C: todas as especialidades (19); PC: 1-18 } \\
\text { especialidades; NC: nenhuma especialidade; ou não se aplica. }\end{array}$ \\
\hline
\end{tabular}


Quadro 1 Continuação...

\begin{tabular}{|c|c|c|c|c|}
\hline Abordagem & Dimensão & Critérios & Pontuação & Padrão de julgamento \\
\hline \multirow{2}{*}{ 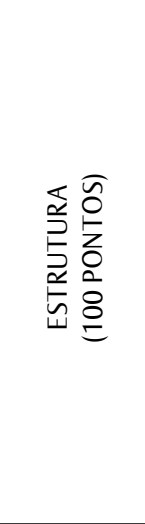 } & \multirow{2}{*}{ 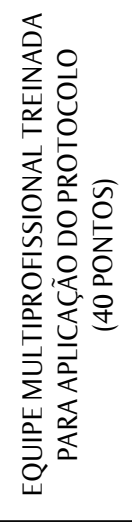 } & $\begin{array}{l}\text { Existência } \\
\text { de equipe } \\
\text { multiprofissional } \\
\text { (10 pontos) }\end{array}$ & $\begin{array}{l}C=10 \\
P C=1-9 \\
N C=0\end{array}$ & $\begin{array}{l}\text { Existência de equipe multiprofissional completa na USF (médico, } \\
\text { enfermeiro, técnico de enfermagem, odontólogo, auxiliar de cirurgião } \\
\text { dentista, dentista, agentes comunitários de saúde). Padrão: C: todos os } \\
\text { profissionais (6); PC: 1-5 profissionais; NC: nenhum profissional; } \\
\text { Existência de equipe multiprofissional completa no Nasf (pediatra, } \\
\text { fisioterapeuta, nutricionista, psicólogo, farmacêutico). Padrão: } \\
\text { C: todos os profissionais (5); PC: 1-4 profissionais; NC: nenhum } \\
\text { profissional. }\end{array}$ \\
\hline & & $\begin{array}{l}\text { Capacitação } \\
\text { (25 pontos) }\end{array}$ & $\begin{array}{l}C=30 \\
P C=1-29 \\
N C=0\end{array}$ & $\begin{array}{l}\text { - } \quad \text { Número de profissionais capacitados por USF. Padrão: C: todos; PC: 1-5 } \\
\text { profissionais; NC: nenhum profissional; ou não se aplica; } \\
\text { - Registro de treinamento realizado com os profissionais responsáveis } \\
\text { pela condução do atendimento (análise documental) } \\
\text { (conformidade: } 1 \text { capacitação por ano); } \\
\text { - Participação em reuniões egrupos de trabalho referentes à } \\
\text { implantação do Protocolo (análise documental). Padrão: C: bimensal; } \\
\text { PC: trimestral-semestral; NC: nenhuma. }\end{array}$ \\
\hline \multirow{4}{*}{ 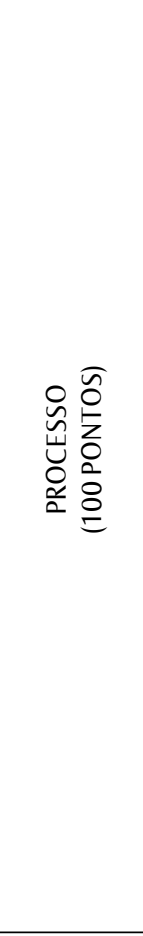 } & \multirow{4}{*}{ 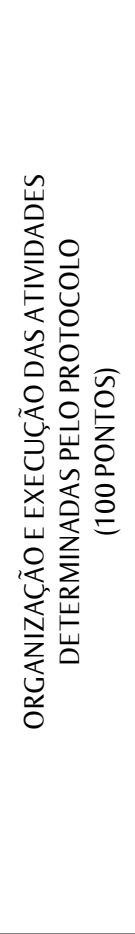 } & $\begin{array}{l}\text { Educação em } \\
\text { saúde } \\
(25 \text { pontos) }\end{array}$ & $\begin{array}{l}C=25 \\
P C=1-24 \\
N C=0\end{array}$ & $\begin{array}{l}\text { - Realização de atividades de educação em saúde voltadas para a } \\
\text { - } \quad \text { Autodçaca exposta aos contaminantes (atas e registros da USF); } \\
\text { atividades de educação em saúde; } \\
\text { - } \quad \text { Realização de atividades de educação em saúde voltadas para a } \\
\text { população exposta aos contaminantes (atas e registros do Nasf). }\end{array}$ \\
\hline & & $\begin{array}{l}\text { Monitoramento } \\
\text { dos casos } \\
(25 \text { pontos) }\end{array}$ & $\begin{array}{l}C=25 \\
P C=1-24 \\
N C=0\end{array}$ & $\begin{array}{l}\text { - Número de pacientes acolhidos que realizaram mais de uma } \\
\text { consulta (dados das fichas de avaliação) (conformidade: 217); } \\
\text { - Número de pacientes acolhidos que realizaram exames } \\
\text { preliminares (dados das fichas de Avaliação) (conformidade: 217). }\end{array}$ \\
\hline & & $\begin{array}{l}\text { Marcação de } \\
\text { consultas e } \\
\text { exames referentes } \\
\text { às condutas } \\
\text { adotadas e } \\
\text { preconizadas pelo } \\
\text { Protocolo } \\
\text { ( } 25 \text { pontos) } \\
\end{array}$ & $\begin{array}{l}C=25 \\
P C=1-24 \\
N C=0\end{array}$ & $\begin{array}{l}\text { - Registro de marcação de exames nos casos em que o médico } \\
\text { formulou suspeita diagnóstica (número encontrado a partir das } \\
\text { fichas de avaliação). }\end{array}$ \\
\hline & & $\begin{array}{l}\text { Ações de } \\
\text { vigilância } \\
\text { (25 pontos) }\end{array}$ & $\begin{array}{l}C=25 \\
P C=1-24 \\
N C=0\end{array}$ & $\begin{array}{l}\text { - } \quad \text { Realização da dosagem de metais pesados na água de abastecimento } \\
\text { - } \quad \text { Réblico e de fontes alternativas (conforo da identificação e do cadastramento de anual); } \\
\text { contaminado (conformidade: áreas identificadas a cada ano e } \\
\text { cadastramento de novas áreas, se existirem). Padrão: atualização anual; } \\
\text { - } \quad \text { Realização do Vigiagua - } 432 \text { amostras por ano, segundo o Sisagua. } \\
\text { Padrão: C: } 100 \% \text { das amostras coletadas e analisadas; PC: } 50-90 \% \text {; } \\
\text { NC: } 1-49 \% \text {. }\end{array}$ \\
\hline \multirow{2}{*}{ 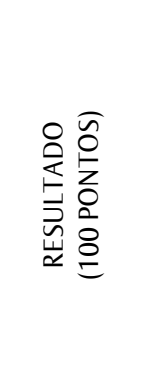 } & \multirow{2}{*}{ 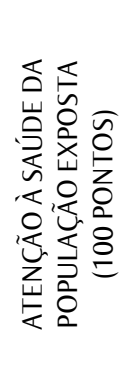 } & $\begin{array}{l}\text { Identificação } \\
\text { e busca dos } \\
\text { expostos } \\
\text { (50 pontos) }\end{array}$ & $\begin{array}{l}C=50 \\
P C=1-49 \\
N C=0\end{array}$ & $\begin{array}{l}\text { - Evidência do atendimento - comparar o número estimado da } \\
\text { população em risco (8.661) com o número de fichas de avaliação das } \\
\text { condições de saúde do paciente preenchidas (conformidade: em } 2 \\
\text { anos toda a população seria atendida); } \\
\text { Dados do Sinan evidenciando a notificação dos casos identificados } \\
\text { (intoxicação exógena) (padrão: atualização anual do Sistema). }\end{array}$ \\
\hline & & $\begin{array}{l}\text { Acompanhamento } \\
\text { da população } \\
\text { exposta } \\
\text { (50 pontos) }\end{array}$ & $\begin{array}{l}C=50 \\
P C=1-49 \\
N C=0\end{array}$ & $\begin{array}{l}\text { - Número de pessoas que retornaram para segunda consulta (dados } \\
\text { das fichas de avaliação) (conformidade: todas as } 217 \text { pessoas } \\
\text { acolhidas retornaram para uma segunda consulta); } \\
\text { - Registro no prontuário do resultado dos exames. }\end{array}$ \\
\hline
\end{tabular}

C: conforme; PC: parcialmente conforme; NC: não conforme; USF: Unidade de Saúde da Família; Nasf: Núcleo de Apoio à Saúde da Família; Vigiagua: Vigilância da Qualidade da Água para Consumo Humano; Sisagua: Sistema de Informação de Vigilância da Qualidade da Água para Consumo Humano; Sinan: Sistema de Informação de Agravos de Notificação; TSH: hormônio estimulante da tiroide; ALA-U: ácido delta-aminolevulínico, urina; ECG: eletrocardiograma; PSA: antígeno prostático específico; FSH: hormônio folículo-estimulante; Gama GT: gamaglutamiltransferase; LH: hormônio luteinizante; USG: ultrassonografia; PCR: proteína C-reativa; T3: triiodotironina; T4: tiroxina. 


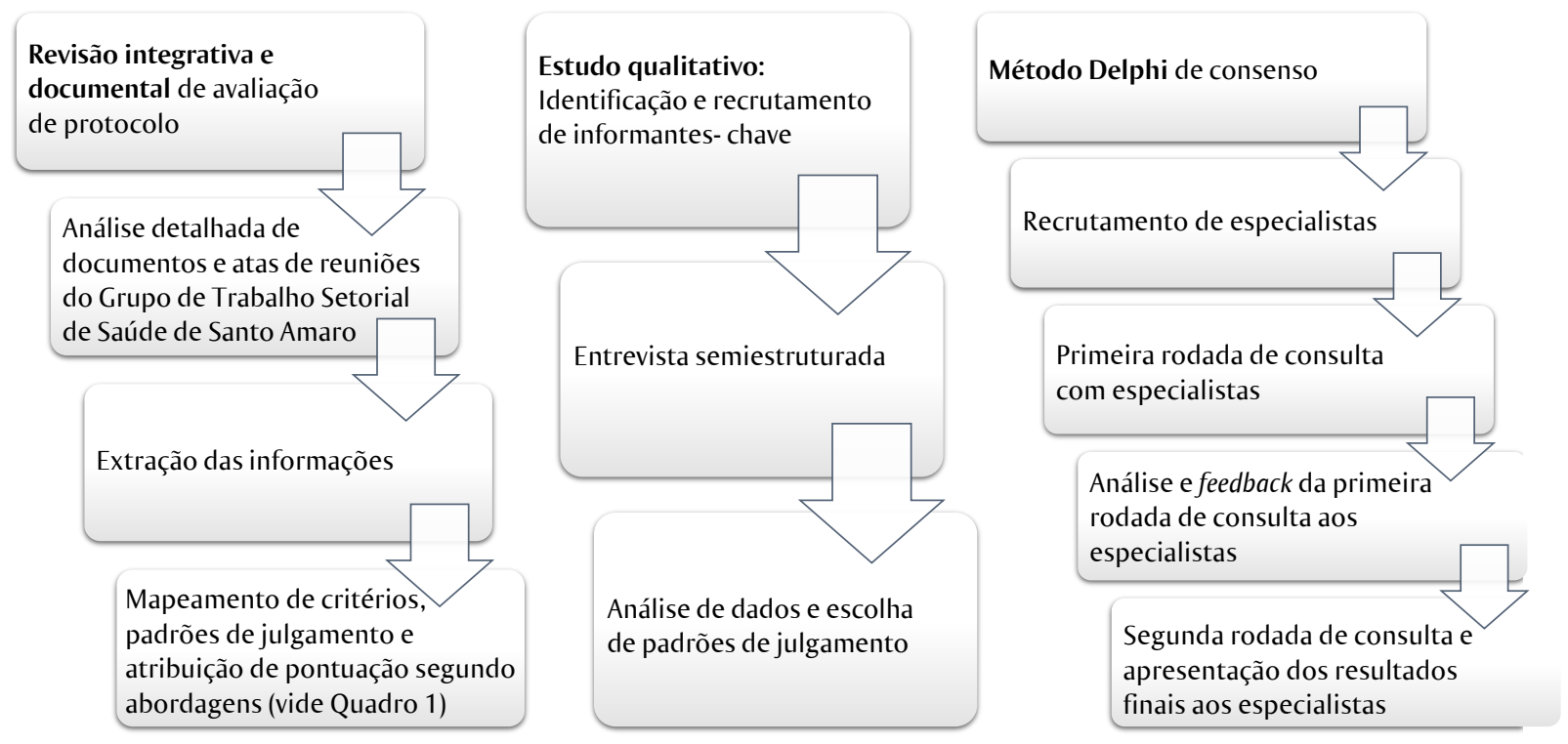

Figura 2 Fluxograma para o desenvolvimento da matriz de avaliação da implantação do Protocolo utilizando o método de Delphi

A alta rotatividade dos profissionais que participaram do Grupo de Trabalho Setorial de Saúde de Santo Amaro (GTSS) desde o início de sua implantação resultou em um número reduzido de especialistas disponíveis para o estudo. O método Delphi modificado foi utilizado na primeira rodada, quando foram realizadas entrevistas face a face, seguindo um roteiro semiestruturado. A segunda rodada seguiu o mesmo processo do Delphi clássico ${ }^{15}$, incorporando as mudanças sugeridas na primeira rodada. Uma nova matriz foi reenviada para a segunda rodada de avaliação pelos especialistas.

Foi solicitado aos respondentes que avaliassem a matriz de julgamento tomando por base as ações e os objetivos previstos no Protocolo. Os respondentes desconheciam os demais partícipes do processo de avaliação; todos receberam individualmente o feedback das respostas para proceder à reavaliação da matriz proposta; e o consenso foi obtido usando-se o critério estatístico simples. Esses procedimentos foram necessários para assegurar a autenticidade do método ${ }^{15}$. A partir da matriz acordada pelos especialistas, foram elaborados os questionários das entrevistas.

Os dados primários foram coletados por um dos pesquisadores. Um total de 13 informantes-chave foram entrevistados, sendo cinco profissionais de saúde coordenadores das USF, um coordenador da regulação, um coordenador da vigilância em saúde do município, um coordenador do Núcleo de Apoio à Saúde da Família (Nasf), o secretário municipal de Saúde, e quatro integrantes do GTSS (em nível estadual). Foram aplicados também quatro formulários específicos contendo informações de identificação, infraestrutura disponível e atividades desenvolvidas por alguns serviços que compõem a rede de saúde do município: USF, Nasf, regulação e vigilância sanitária, ambiental e de saúde do trabalhador do município. Também foram coletadas informações contidas nas Fichas de Avaliação das Condições de Saúde (Facs), que eram obtidas nas USF, e nos exames realizados pelo Laboratório Central de Saúde Pública (Lacen) entre os anos de 2010 e 2015, disponibilizados pela Secretaria Municipal de Saúde. Entre 2010 e 2015, foram identificadas 217 Facs nas USF e verificados 1.080 exames no Lacen, correspondentes a 216 pessoas de Santo Amaro. Foram utilizadas ainda informações de atas de reuniões e relatórios do GTSS, dos Sistemas de Vigilância em Saúde Ambiental - Vigilância da Qualidade da Água para Consumo Humano (Vigiagua) e Vigilância em Saúde de Populações Expostas a Solo Contaminado (Vigisolo) - e do Sistema de Informação de Agravos de Notificação (Sinan).

Para aferir o grau de implantação do Protocolo, conforme o modelo lógico (Figura 1), foi definida uma pontuação para cada critério, de modo que a soma obtida a partir desses critérios revelaria o valor das dimensões de cada abordagem relacionada e, finalmente, o escore final foi calculado, resultando 
em uma porcentagem (Quadro 1). A pontuação foi obtida com base nas informações dos formulários aplicados nas unidades, fazendo-se soma por critério de julgamento para obtenção do escore final.

Vê-se a seguir a descrição de cada pontuação e do escore final, onde $\sum$ indica o somatório do item:

- Pontuação máxima de cada dimensão = $\sum$ (pontuação máxima de cada critério)

- Pontuação alcançada de cada dimensão = $\sum$ (pontuação alcançada de cada critério)

- Escore final = (pontuação alcançada/pontuação máxima) $\times 100$

De posse do escore final, foram utilizados parâmetros de classificação da implantação de acordo com a porcentagem atingida: implantação inexistente ou insatisfatória (0-25\%), implantação incipiente (26-50\%), implantação intermediária (51-75\%) e implantação avançada (76-100\%).

\section{Aspectos éticos}

O projeto foi submetido ao Comitê de Ética em Pesquisa da Faculdade de Medicina da Universidade Federal da Bahia e aprovado pelo Parecer no 934.168. Para a abordagem dos entrevistados observaram-se os aspectos éticos previstos na Resolução CNS $\mathrm{n}^{\circ} 466 / 2012$, com aplicação do termo de consentimento livre e esclarecido. Os participantes foram informados sobre os objetivos da pesquisa e sobre o uso das informações coletadas exclusivamente para este estudo.

\section{Resultados e discussão}

As principais ações realizadas entre os anos de 2003 e 2015 pelo GTSS estão sintetizadas no Quadro 2. Ao longo do processo de implantação do Protocolo observaram-se problemas relacionados à efetividade da assistência e notou-se que não foi realizada qualquer avaliação nos serviços.

Quadro 2 Síntese das principais ações desenvolvidas pelo Grupo de Trabalho Setorial de Saúde de Santo Amaro, Bahia, Brasil, de 2003 a 2014

\begin{tabular}{|c|c|}
\hline 2003 & $\begin{array}{l}\text { Partindo da avaliação de risco elaborada pelo Ministério da Saúde, que identificou os grupos expostos e sinalizou medidas a serem } \\
\text { adotadas, o GTSS elaborou o Plano de Ação intitulado “Atenção e Vigilância à Saúde da População Exposta a chumbo, cádmio, } \\
\text { zinco e cobre em Santo Amaro da Purificação", indicando atividades a serem implantadas entre os anos de } 2004 \text { e 2006, com as } \\
\text { seguintes linhas de atuação: educação e saúde, vigilância e atenção à saúde, e gestão e articulação inter e intrasetorial. }\end{array}$ \\
\hline 2005 & $\begin{array}{l}\text { nstituída a Comissão Intersetorial da Purificação, pelo Decreto nº 9.295/2005, com objetivo de sugerir e implementar } \\
\text { ôes que promovessem mudança do quadro socioambiental e de saúde em Santo Amaro. }\end{array}$ \\
\hline 2007 & $\begin{array}{l}\text { Publicação da Portaria no } 3.487 \text {, instituindo o Grupo de Trabalho em Saúde do Programa Intersetorial de } \\
\text { Purificação de Santo Amaro (GTINTER). } \\
\text { Realização de reuniões sistemáticas propondo organização de estratégias de intervenção na problemática de Santo Amaro. } \\
\text { Realização de oficina para a elaboração do Protocolo. } \\
\text { Atendimentos a trabalhadores no Ambulatório da Divisão de Atenção à Saúde do Trabalhador (Divast) da } \\
\text { Secretaria de Saúde do Estado da Bahia. } \\
\text { Encaminhamento de trabalhadores para realização de exames radiológicos e laboratoriais especializados (eletroforese de } \\
\text { hemoglobina, TSH, dosagem de arsênico na urina, ferro sérico, cortisol, ALA-U, transferrina, testosterona, ECG (em crianças), } \\
\text { PSA, FSH, raio X (em crianças e adultos), Gama GT, LH, USG morfológica (gestantes), bilirrubinas, PCR, USG (abdome com } \\
\text { Doppler), amilase, látex, USG de próstata, coagulograma, ácido úrico, eletroneuromiografia, fosfatase alcalina, espermograma, } \\
\text { densitometria óssea, T3, T4 livre, mielograma, e audiometria). } \\
\text { Compras de insumos, reagentes e equipamentos para a realização de exames. } \\
\text { Atividades de educação continuada das equipes de Saúde da Família e acompanhamento do processo no Ministério Público. }\end{array}$ \\
\hline 2010 & $\begin{array}{l}\text { Capacitação em nível municipal visando à implantação do Protocolo, com apresentação dos instrumentos e fluxogramas de } \\
\text { condutas e rotinas aos profissionais de saúde. }\end{array}$ \\
\hline 2011 & $\begin{array}{l}\text { Ações visando informar a população sobre a importância da implantação do Protocolo, bem como entrega das Facs e } \\
\text { distribuição de cópias do Protocolo às equipes de USF de Santo Amaro. }\end{array}$ \\
\hline 2012 & $\begin{array}{l}\text { Elaboração de um Plano de Ação para a Implantação do Protocolo nas USF do município e de planilha para acompanhamento } \\
\text { da execução das ações de atenção à saúde. }\end{array}$ \\
\hline 2013 & $\begin{array}{l}\text { Discussão sobre o preenchimento e a finalidade das Facs, enaltecendo sua importância para os encaminhamentos previstos } \\
\text { nos fluxogramas. } \\
\text { São realizadas atividades de educação em saúde e orientação do fluxo de referência e contrarreferência dos atendimentos. }\end{array}$ \\
\hline 2014 & $\begin{array}{l}\text { Aplicação das Facs nas USF. } \\
\text { Relato de dificuldades no fluxo das referências de média e alta complexidade do município e pactuações firmadas entre } \\
\text { estado e município. }\end{array}$ \\
\hline
\end{tabular}

GTSS: Grupo de Trabalho Setorial de Saúde de Santo Amaro; Facs: Fichas de Avaliação das Condições de Saúde; USF: Unidades de Saúde da Família; TSH: hormônio estimulante da tiroide; ALA-U: ácido delta-aminolevulínico, urina; ECG: eletrocardiograma; PSA: antígeno prostático específico; FSH: hormônio folículo-estimulante; Gama GT: gamaglutamiltransferase; LH: hormônio luteinizante; USG: ultrassonografia; PCR: proteína C-reativa; T3: triiodotironina; T4: tiroxina. 
A verificação do grau de implantação do Protocolo buscou contribuir para evidenciar dificuldades e apontar intervenções na assistência e vigilância em saúde da população e do trabalhador. Com base na matriz de julgamento, que definiu um sistema de escores para determinar o grau de implantação (Quadro 1), o escore final no município de Santo Amaro foi de 22,3\% (Quadro 3), considerado insatisfatório, segundo a classificação adotada. Em relação às abordagens, a "estrutura” obteve $38 \%$ dos pontos estabelecidos, "processo" obteve 25\%, e a categoria "resultados" teve o menor percentual na avaliação: apenas 4\%.

Quadro 3 Matriz de pontuação da implantação do Protocolo de Vigilância à Saúde da População Exposta ao Chumbo, Cádmio, Cobre e Zinco em Santo Amaro, Bahia, Brasil

\begin{tabular}{|c|c|c|c|c|c|c|c|c|c|}
\hline Abordagem & Dimensões & Critérios & Máximo & $\begin{array}{c}\text { Total } \\
\text { alcançado }\end{array}$ & Máximo & $\begin{array}{c}\text { Total } \\
\text { alcançado }\end{array}$ & Máximo & $\begin{array}{c}\text { Total } \\
\text { alcançado }\end{array}$ & $\%$ \\
\hline (a) & (d) & (c) & (c) & (c) & (d) & (d) & (a) & (a) & (a) \\
\hline \multirow{6}{*}{ Estrutura } & \multirow[t]{2}{*}{ Infraestrutura } & $\begin{array}{l}\text { Estrutura física } \\
\text { para execução das } \\
\text { atividades propostas } \\
\text { pelo Protocolo }\end{array}$ & 20 & 11 & \multirow[t]{2}{*}{40} & \multirow[t]{2}{*}{15} & \multirow{6}{*}{100} & \multirow{6}{*}{38} & \multirow{6}{*}{$38 \%$} \\
\hline & & $\begin{array}{l}\text { Diagnóstico e } \\
\text { acompanhamento } \\
\text { dos pacientes }\end{array}$ & 20 & 4 & & & & & \\
\hline & \multirow{2}{*}{$\begin{array}{l}\text { Acesso ao serviço } \\
\text { e ao atendimento/ } \\
\text { cobertura }\end{array}$} & Acesso geográfico & 5 & 2 & \multirow[b]{2}{*}{25} & \multirow[b]{2}{*}{10} & & & \\
\hline & & $\begin{array}{l}\text { Acesso a } \\
\text { atendimento e } \\
\text { exames }\end{array}$ & 20 & 8 & & & & & \\
\hline & \multirow{2}{*}{$\begin{array}{l}\text { Equipe } \\
\text { multiprofissional } \\
\text { treinada para } \\
\text { a aplicação do } \\
\text { Protocolo }\end{array}$} & $\begin{array}{l}\text { Existência de equipe } \\
\text { multiprofissional }\end{array}$ & 10 & 9 & \multirow[b]{2}{*}{35} & \multirow[b]{2}{*}{13} & & & \\
\hline & & Capacitação & 25 & 4 & & & & & \\
\hline \multirow{4}{*}{ Processo } & \multirow{4}{*}{$\begin{array}{l}\text { Organização } \\
\text { e execução } \\
\text { das atividades } \\
\text { determinadas pelo } \\
\text { Protocolo }\end{array}$} & Educação em saúde & 25 & 13 & \multirow{4}{*}{100} & \multirow{4}{*}{25} & \multirow{4}{*}{100} & \multirow{4}{*}{25} & \multirow{4}{*}{$25 \%$} \\
\hline & & $\begin{array}{l}\text { Monitoramento dos } \\
\text { casos }\end{array}$ & 25 & 1 & & & & & \\
\hline & & $\begin{array}{l}\text { Marcação de } \\
\text { consultas e exames } \\
\text { referentes às } \\
\text { condutas adotadas } \\
\text { e preconizadas pelo } \\
\text { Protocolo }\end{array}$ & 25 & 8 & & & & & \\
\hline & & Ações de vigilância & 25 & 3 & & & & & \\
\hline \multirow{2}{*}{ Resultados } & \multirow{2}{*}{$\begin{array}{l}\text { Atenção à saúde da } \\
\text { população exposta }\end{array}$} & $\begin{array}{l}\text { Identificação } \\
\text { (acolhimento) e } \\
\text { busca da população } \\
\text { exposta }\end{array}$ & 50 & 2 & \multirow[t]{2}{*}{100} & \multirow[t]{2}{*}{4} & \multirow[t]{2}{*}{100} & \multirow{2}{*}{4} & \multirow[t]{2}{*}{$4 \%$} \\
\hline & & $\begin{array}{l}\text { Acompanhamento } \\
\text { da população } \\
\text { exposta }\end{array}$ & 50 & 2 & & & & & \\
\hline \multirow{2}{*}{\multicolumn{4}{|c|}{ Classificação da implantação }} & \multicolumn{3}{|c|}{ TOTAL } & 300 & 67 & \\
\hline & & & & \multicolumn{2}{|c|}{$22,3 \%$} & & & & \\
\hline
\end{tabular}


Com referência à "estrutura", suas dimensões alcançaram os seguintes percentuais: infraestrutura: $37,5 \%$; acesso ao serviço e ao atendimento/cobertura: $40 \%$; e equipe multiprofissional treinada para a aplicação do Protocolo: $37,1 \%$. Na dimensão "infraestrutura”, a estrutura física para execução das atividades propostas apresentava-se em conformidade com os padrões definidos no que diz respeito ao número de salas de acordo com a população a ser atendida, aos ambientes para consultas individualizadas e aos procedimentos de serviços específicos nas USF visitadas; no entanto, a maioria delas carece de sala específica para atividades coletivas de educação em saúde, além de recursos materiais e tecnológicos para a realização dos atendimentos. Já no que diz respeito ao "diagnóstico e acompanhamento dos pacientes", obteve-se pontuação muito baixa (4 de um total de 20 pontos), decorrente da baixa capacidade para realização de exames de detecção de metais, assim como da baixa disponibilidade para realização de consultas, além da indisponibilidade de laboratório próprio ou conveniado para a realização da maior parte dos exames indicados pelo Protocolo.

A dificuldade de acesso geográfico, critério da dimensão "acesso ao serviço e ao atendimento", pode ter sido um fator limitante para a triagem e o acompanhamento dos usuários. O acompanhamento da população exposta a metais deve ser realizado primordialmente pelas USF, cuja localização deve ser de fácil acesso e próxima à residência dos usuários. As cinco USF avaliadas atendem aos padrões de conformidade de localização geográfica. Em contrapartida, o mesmo não se verifica em relação aos laboratórios de análises clínicas, principalmente para a realização de exames referentes à contaminação por metais. Profissionais relataram dificuldades para prover o transporte das pessoas que, na maioria dos casos, teriam que se deslocar até Salvador para realizar os exames. Um ponto positivo é que as USF com maior número de atendimentos, Sacramento e Caixa d'Água, se situavam nas áreas consideradas de maior risco ambiental, próximas da sede da Cobrac/Plumbum.

Verificou-se que 217 pacientes tiveram fichas de atendimento abertas nas UBS, porém apenas 115 (53\%) realizaram avaliação médica inicial. Conforme descrito na metodologia, o quantitativo de 8.661 pessoas a serem acompanhadas foi estimado para este estudo. Para esse cálculo, foram levados em conta a estimativa de 2.570 famílias afetadas e o estudo das rotas de exposição descritas no Protocolo ${ }^{5}$. Entretanto, não há no documento ${ }^{5}$ o cálculo do número de pessoas a serem atendidas pelo Protocolo, nem de consultas previstas, sendo adotada, neste estudo, a medida de ao menos uma consulta por pessoa.

A baixa articulação entre atendimento clínico, serviços de apoio diagnóstico e ações de vigilância ambiental fica evidenciada no processo de implantação do Protocolo. As Facs foram obtidas nas USF, e os resultados dos exames na Secretaria de Saúde Municipal, ou seja, em diferentes fontes de informação. Entre 2010 e 2015, considerando 2010 como o ano de início da implantação do Protocolo, foram identificadas 217 Facs nas USF, correspondentes a $2,5 \%$ do total previsto (8.661). No Lacen, localizaram-se 1.080 exames de 216 habitantes de Santo Amaro relacionados ao Protocolo. Contudo, entre os que realizaram exames no Lacen, apenas 13 (6\%) possuíam Facs nas USF do município. Na análise das 217 Facs, identificou-se a falta de registros de resultados de exames em 213 (98\%) delas, e nenhum registro de solicitação de consultas subsequentes ou de encaminhamento a especialistas. Esses resultados foram fundamentais na abordagem do "processo" para que o critério "monitoramento dos casos" tivesse pontuação muito baixa (1 de 25).

De acordo com o fluxo de atendimento estabelecido no Protocolo, os pacientes deveriam primeiro ser atendidos nas USF, onde seriam preenchidas as Facs, depois receber atendimento médico, e só então poderiam ser encaminhados ao Lacen para realização dos exames. O que se constatou é que 203 moradores de Santo Amaro realizaram algum exame vinculado ao Protocolo, mas não possuíam Facs nas unidades de saúde do município. Isso denota o não cumprimento do fluxograma planejado pelo Protocolo, como referido pelos técnicos do Lacen. Essa situação levou o Laboratório a suspender a realização de exames para detecção de chumbo e outros metais no sangue até que o fluxo previsto fosse respeitado. Essa descrição detalhada aponta a desarticulação entre apoio diagnóstico laboratorial, atendimento clínico e vigilância ambiental. A análise desse processo foi de tamanha relevância que resultou em um outro artigo, de caráter qualitativo, que teve como informantes membros do GTSS que acompanharam a implantação do protocolo ${ }^{14}$.

Verificou-se ainda que, das 18 especialidades médicas indicadas para serem disponibilizadas na rede de atendimento público, nove (50\%), em média, estavam disponíveis para marcação em âmbito local ou por meio de parcerias com outros municípios.

A dimensão "acesso ao serviço e ao atendimento/ cobertura" obteve 10 pontos de um total de 25. Em relação aos seus critérios, o "acesso a exames médicos" foi referido como insuficiente, pois, dos exames preliminares previstos pelo Protocolo, o exame de quantificação dos metais (chumbo, cádmio, cobre e zinco) não se encontrava disponível e, quanto aos exames complementares, a maior parte $(79,7 \%)$ não estava disponível no âmbito da rede laboratorial do município ou em seus conveniados. 
Outros dois critérios avaliados na abordagem da estrutura dizem respeito à equipe multiprofissional. Apesar da existência de equipes completas, é reduzido o número de profissionais capacitados para lidar com o manejo dos casos conforme preconiza o Protocolo e, em geral, apenas os coordenadores das unidades receberam treinamento. Para Ribeiro ${ }^{17}$, a qualificação dos profissionais das equipes de saúde constitui uma ação estratégica para transformação das práticas de saúde. Em Santo Amaro, a falta de continuidade da capacitação dos profissionais e o incipiente sistema de referência e contrarreferência podem ter contribuído para uma baixa adesão às ações determinadas pelo Protocolo.

Pesquisa anterior revelou que, na Bahia, aproximadamente $75,5 \%$ dos médicos e $39,1 \%$ dos enfermeiros com atuação em equipes de Saúde da Família nos anos de 2001 e 2002 contavam menos de seis meses de tempo de permanência na equipe ${ }^{18}$. No caso de Santo Amaro, a alta rotatividade de profissionais contratados para atuar na atenção básica constitui-se em entrave na capacitação das equipes para o exercício de novas práticas de saúde, procedimentos e atividades orientados pelo Protocolo.

A abordagem "processo", que alcançou 25 pontos dos 100 possíveis, teve a sua avaliação baseada na dimensão "organização e execução das atividades determinadas pelo Protocolo". O primeiro critério observado foi a realização de atividades de educação em saúde e, nesse item, verificou-se que o Nasf realizava esse tipo de atividade conforme o planejado.

Nas equipes de Saúde da Família, embora a maioria dos profissionais tenha referido a realização de ações de educação em saúde, estas só ocorreram em momentos pontuais e, em uma das unidades, foram feitas apenas uma vez, entre 2010 e 2014, fato que contribuiu para a menor pontuação nesse quesito. Os profissionais alegam falta de estrutura, de recursos humanos e de tempo para realizar esse tipo de atividade. No Brasil, a prática de atividades educativas ainda necessita ser ampliada, dada a sua importância na promoção da saúde. Há evidências de que esse tipo de atividade é praticado pelos profissionais das equipes de Saúde da Família numa média que varia de $63 \%$ a $77 \%{ }^{18}$.

É evidente a necessidade de maior espaço para ações de comunicação de risco nos projetos de intervenção em saúde e ambiente em Santo Amaro, pois estas nos parecem fundamentais para o sucesso da implantação do Protocolo. A lacuna da interlocução com a comunidade é apontada por alguns autores ${ }^{4,19}$ e também em estudo recentemente publicado que teve como objetivo identificar a percepção da população em relação à contaminação do solo pela escória de metais pesados ${ }^{20}$. Nesse estudo, os autores concluem que há evidências inequívocas de que a escória produzida pela fundição de chumbo continua sendo um importante poluente do solo urbano, representando um risco para a saúde da população, especialmente para as crianças. Entretanto, os moradores ainda desconhecem informações sobre os riscos à saúde relacionados à escória presente em seus domicílios. Em 2018, Carvalho e colaboradores ${ }^{20}$ reiteraram a importância da participação da população na discussão das propostas de soluções para problemas de contaminação do solo em sua cidade.

Na interlocução dos serviços de saúde com a comunidade, as entrevistas e a pesquisa documental apontam espaços formais de controle social no GTSS. Ao longo do tempo, a participação da sociedade civil nesses espaços, antes ocupados principalmente por membros da Associação das Vítimas da Contaminação por Chumbo, Cádmio, Mercúrio e Outros Elementos Químicos (Avicca), foi se tornando pequena. Um dos motivos para o esvaziamento dos espaços de participação social pode ter sido as falhas quanto à governança e à comunicação de risco para a população exposta ${ }^{4,19}$. Outra explicação pode ser decorrente das poucas intervenções e indenizações obtidas ao longo do tempo, apesar dos estudos comprovando o nexo entre exposição e doença ${ }^{21}$. Também há evidências de que parte das pessoas apresenta dúvidas sobre os efeitos dos metais pesados na saúde, preferindo o silêncio e a negação da contaminação como forma de garantir a "segurança alimentar e nutricional" da população exposta ${ }^{22}$.

A avaliação buscou, como um dos critérios da matriz de julgamento, abordar os aspectos referentes a atividades de educação em saúde, no que tange ao processo, enquanto forma de avaliar a interlocução do serviço de saúde com a comunidade. Mas reconhecemos que avaliar apenas esse critério é insuficiente, sendo esta uma das limitações deste estudo. Tal aspecto merece uma outra etapa da investigação, que deve ser aprofundada em estudos posteriores, buscando investigar o que pensa a população sobre a implantação do Protocolo.

Quanto às ações de vigilância, constatou-se que o município não cumpre as exigências de monitoramento quanto à dosagem de metais pesados na água destinada ao abastecimento público e de fontes alternativas. Informações do Lacen atestam que chegou a ser montado um laboratório de toxicologia para fazer análise de metais em água; entretanto, as amostras não eram enviadas pelo município. Além disso, o técnico responsável pela análise mudava de setor e não dava continuidade ao serviço. Posteriormente ocorreu problema no equipamento devido à falta de manutenção.

Com a análise dos sistemas Vigisolo e Vigiagua foi possível verificar déficit no cumprimento do cadastro de áreas de solo contaminadas, assim como no 
cumprimento de determinações sobre a qualidade da água para consumo humano. Os registros apontam que somente em 2007 foram realizados a identificação e o cadastramento das áreas de solo contaminadas.

Importa destacar que a abordagem "resultados", nesta pesquisa, refere-se às metas atingidas em curto espaço de tempo na dimensão "atenção à saúde da população exposta”. Apenas 4 pontos foram alcançados de um total de 100 nessa abordagem. Os critérios pontuados referem-se à identificação e busca da população exposta, evidenciada pela presença de Facs nas USF, e ao acompanhamento dessa população. Cabe destacar que as várias falhas no preenchimento das Facs, citadas anteriormente, permitem evidenciar a precariedade na assistência, seja em relação às consultas médicas ou aos exames e registros no Sinan.

O Protocolo recomenda realizar a notificação dos casos suspeitos utilizando a Ficha de Investigação Epidemiológica de Intoxicações Exógenas do SinanWeb, do Ministério da Saúde. Entretanto, os profissionais das USF informaram não ter realizado notificações ao Sinan no período. Existem evidências de que ações de vigilância epidemiológica no âmbito das USF têm sido negligenciadas na organização do processo de trabalho e delegadas a profissionais especializados e/ou de nível central, o que contribui para que os profissionais das USF não se apropriem das atividades e dos resultados produzidos ${ }^{23,24}$.

Donabedian $^{25}$ traz como relevante para avaliação dos critérios de qualidade a disponibilidade e qualidade dos registros. Nesse sentido, deve ser levado em conta o preenchimento deficitário de registros de saúde contidos nas Facs e utilizados no acompanhamento da população exposta nas USF de Santo Amaro, o que implicou a atribuição de pontuação baixa em critérios de "monitoramento", "marcação de consultas e exames", "identificação e busca de expostos" e "acompanhamento da população”. Conclui-se que a incompletude no preenchimento das Facs traduz-se em baixa qualidade da assistência prestada.

Dentre as limitações deste estudo está o pequeno número de participantes no método Delphi. Entretanto, não há concordância quanto ao número mínimo necessário de especialistas para compor o painel desse método, tampouco uma classificação do que seria uma amostra grande ou pequena ${ }^{26}$.

Os resultados deste estudo evidenciam que a implantação do protocolo no município de Santo Amaro é considerada insatisfatória, com o escore final de $22,3 \%$, apesar do trabalho realizado pelas diferentes instâncias partícipes do GTSS, que procuraram, dentro de suas limitações, organizar os serviços para cumprir as recomendações contidas no Protocolo.

\section{Conclusões}

Os critérios utilizados para avaliar a implantação do Protocolo de Vigilância e Atenção à Saúde da População Exposta ao Chumbo, Cádmio, Cobre e Zinco no município de Santo Amaro possibilitaram classificá-la como insatisfatória.

Foram evidenciadas fragilidades de recursos físicos e materiais, de organização das estratégias, de práticas clínicas e de vigilância ambiental e sanitária durante o processo de implantação do Protocolo em comparação com as recomendações e normatizações. Portanto, as condições da estrutura e do processo de assistência comprometem a qualidade da atenção à população exposta a contaminantes. Dessa forma, mesmo considerando as limitações deste trabalho, as evidências dos resultados encontrados reúnem elementos para o conhecimento e a crítica das abordagens e dos métodos utilizados nos serviços de atenção primária à saúde com foco em saúde ambiental e do trabalhador, ao mesmo tempo que trazem o debate acerca da qualidade dos serviços e da assistência prestada à saúde da população e da efetividade das ações propostas.

Ressalta-se o grande esforço empenhado pelas equipes envolvidas na elaboração desse Protocolo. Neste estudo, buscou-se demonstrar as dificuldades e os avanços na sua implantação, englobando uma rede de serviços que deve estar integrada. Entretanto, concorda-se com Bezerra et al. ${ }^{27}$ quando afirmam que o modelo lógico e a matriz de indicadores utilizados nas diversas pesquisas não devem ser considerados instrumentos definitivos, tendo em vista a complexidade do objeto avaliado e o seu estágio de desenvolvimento. Assim, este estudo constitui-se como uma primeira aproximação da estratégia de implantação da assistência e vigilância da saúde da população de Santo Amaro, tendo as suas diretrizes determinadas no Protocolo.

Entendendo o Protocolo como uma tecnologia do setor de saúde para o enfrentamento da problemática do chumbo e de outros metais em Santo Amaro, este projeto pode ser considerado no contexto da implementation science, à semelhança da atuação na prevenção primária à exposição ao chumbo nos Estados Unidos $^{28}$. Espera-se que os resultados desta avaliação contribuam para repensar as estratégias de vigilância e atenção à saúde ambiental e do trabalhador, como também para alavancar maior interlocução com a população, além de discussões e ações efetivas por parte de profissionais da saúde e gestores das instâncias estadual, municipal e federal.

Os achados deste trabalho podem colaborar para reflexões e discussões entre a população e os profissionais envolvidos na gestão e nos serviços, 
apontando barreiras no processo de assistência e vigilância da saúde e no treinamento dos profissionais para lidar com suas estratégias. Sabendo-se das dificuldades, em nível municipal, no que tange à promoção de assistência e à disponibilidade de recursos adequados, todas as instâncias envolvidas devem construir estratégias no intuito de melhor estruturar uma rede de serviços organizada em prol de uma atenção mais eficiente e de qualidade para a população de Santo Amaro, que há mais de 40 anos sofre com as consequências da contaminação ambiental.

\section{Contribuições de autoria}

Machado LOR, Rego RF, Silva GA, Müller JS e Falcão IR contribuíram na revisão de literatura, no desenho do estudo e na coleta de dados. Machado LOR, Rego RF e Silva GA contribuíram na análise dos dados. Todas as autoras contribuíram na interpretação, elaboração e aprovação da versão final do manuscrito. Todas as autoras assumem integral responsabilidade pelo estudo e pelo conteúdo publicado.

\section{Referências}

1. Magna GAM, Machado SL, Portella RB, Carvalho MF. Chumbo e cádmio detectados em alimentos vegetais e gramíneas no município de Santo Amaro-Bahia. Quim Nova. 2013;36(7):989-97.

2. Agency for Toxic Substances \& Disease Registry. Toxic substances: lead [Internet]. Atlanta: ATSDR; 2011 [citado em 10 jul 2015]. Disponível em: http://www.atsdr.cdc.gov/substances/toxsubstance. asp?toxid $=22$

3. Andrade Lima LRP, Bernardez LA. Characterization of the soil contamination around the former primary lead smelter at Santo Amaro, Bahia, Brazil. Environ Earth Sci. 2017;76(14):470.

4. Andrade M, Moraes L. Contaminação por chumbo em Santo Amaro desafia décadas de pesquisas e a morosidade do poder público. Ambien Soc. 2013;16(2):63-80.

5. Bahia. Secretaria da Saúde. Protocolo de Vigilância e Atenção à Saúde da População Exposta ao Chumbo, Cádmio, Cobre e Zinco em Santo Amaro, Bahia. Salvador: Cesat; 2010.

6. Brasil. Ministério da Saúde. Avaliação de risco à saúde humana por metais pesados em Santo Amaro da Purificação, Bahia. Brasília, DF: Ministério da Saúde; 2003.

7. Figueiredo AMA, Tanaka O. A avaliação no SUS como estratégia de reordenação da saúde. Cad Fundap. 1996;19:98-105.

8. Champagne F, Contandriopoulos AP, Brousselle A, Hartz Z, Denis JL. Avaliação no campo da saúde: conceitos e métodos. In: Brousselle A, Champagne F, Contandriopoulos AP, Hartz Z, organizadores. Avaliação: conceitos e métodos. Rio de Janeiro: Fiocruz; 2011. p. 41-60.

9. Contandriopoulos AP, Champagne F, Denis JL, Pineault R. A avaliação na área de saúde: conceitos e métodos. In: Hartz Z, organizadora. Avaliação em saúde: dos modelos conceituais à prática na análise da implantação de programas. Rio de Janeiro: Fiocruz; 1997. p. 29-47.
10. Brasil. Ministério da Saúde. Secretaria de Atenção Básica à Saúde. Departamento de Atenção Básica. Avaliação na Atenção Básica em Saúde: caminhos da institucionalização. Brasília, DF: Ministério da Saúde; 2005.

11. Hartz Z, Champagne F, Contandriopoulos AP, Leal M. Avaliação do programa materno-infantil: análise da implantação em sistemas locais de saúde no Nordeste do Brasil. In: Hartz Z, organizadora. Avaliação em saúde: dos modelos conceituais à prática na análise da implantação de programas. Rio de Janeiro: Fiocruz; 1997. p. 89-131.

12. Instituto Brasileiro de Geografia e Estatística. Censo demográfico: censo 2010 [Internet]. Rio de Janeiro: IBGE; 2010 [citado em 10 jan 2015]. Disponível em: https:/www.ibge.gov.br/home/ estatistica/populacao/censo2010/tabelas_pdf/total_ populacao_bahia.pdf

13. Fernandes FRC, Bertolino LC, Egler SG, editores. Projeto Santo Amaro - BA: aglutinando ideias, construindo soluções: diagnósticos. Rio de Janeiro: Cetem; 2012.

14. Rego RF, Machado LOR, Silva GA, Falcão IR. Implantação de protocolo de vigilância e atenção à saúde de ex-trabalhadores e população exposta a chumbo, cádmio, cobre e zinco em Santo Amaro, Bahia. Rev Bras Saude Ocup. 2019;44:e28.

15. Keeney S, Hasson F, McKenna HP. A critical review of the Delphi technique as a research methodology for nursing. Int J Nurs Stud. 2001;38(2):195-200.

16. Scarparo AF, Laus AM, Azevedo ALCS, Freitas MRI, Gabriel CS, Chaves LDP. Reflexões sobre a técnica Delphi em pesquisas na enfermagem. Rev Rene. 2012;13(1):242-51.

17. Ribeiro RMM. Avaliação da implantação da Portaria 151 para o diagnóstico da infecção pelo HIV no Brasil [dissertação]. Brasília, DF: Fundação Oswaldo Cruz; 2012.

18. Brasil. Ministério da Saúde. Secretaria de Atenção à Saúde. Departamento de Atenção Básica. Avaliação normativa do Programa Saúde da 
Família no Brasil: monitoramento da implantação e funcionamento das equipes de Saúde da Família: 2001-2002. Brasília, DF: Ministério da Saúde; 2004.

19. Di Giulio GM, Figueiredo BR, Ferreira LC, dos Anjos JASA. Brazilian cases and the debate about risk communication and governance in areas contaminated by lead. Cienc Saude Colet. 2012;17(2):337-49.

20. Carvalho FM, Tavares TM, Lins L. Soil contamination by a lead smelter in Brazil in the view of the local residents. Int J Environ Res Public Health. 2018;15(10):2166.

21. Silvany-Neto AM, Carvalho FM, Tavares TM, Guimaraes GC, Amorim CJ, Peres MF, et al. Lead poisoning among children of Santo Amaro, Bahia, Brazil in 1980, 1985, and 1992. Bull Pan Am Health Organ. 1996;30(1):51-62.

22. Barreto MF, Freitas MCS. Segurança alimentar e nutricional e contaminação ambiental: tabu e estigma. Cienc Saude Colet. 2017;22(2):527-34.

23. Santos SSBS, Melo CMM. Avaliação da descentralização da vigilância epidemiológica para a equipe de Saúde da Família. Cienc Saude Colet. 2008;13(6):1923-32.

24. Cerqueira EM, Assis MMA, Villa TCS, Leite JA. Vigilância epidemiológica no processo de municipalização do sistema de saúde em Feira de Santana-BA. Epidemiol Serv Saude. 2003;12(4):213-23.

25. Donabedian A. Criteria and standards for quality assessment and monitoring. QRB Qual Rev Bull. 1986;12(3):99-108.

26. Williams PL, Webb C. The Delphi technique: a methodological discussion. J Adv Nurs. 1994;19(1):180-6.

27. Bezerra LCA, Freese E, Frias PG, Samico I, Almeida CKA. A vigilância epidemiológica no âmbito municipal: avaliação do grau de implantação das ações. Cad Saude Publica. 2009;25(4):827-39.

28. Rabito FA, White LE, Shorter C. From research to policy: targeting the primary prevention of childhood lead poisoning. Public Health Rep. 2004;119(3):271-8. 